\section{FirSt RECORD OF CINEREOUS VULTURE AEGYPIUS MONACHUS (FALCONIFORMES: ACCIPITRIDAE) FROM SOUTHERN RAJASTHAN, INDIA}

\section{Deependra Singh Shekhawat ${ }^{1}$, Chhaya Bhatnagar ${ }^{2}$, Vijay Kumar Koli ${ }^{3} \&$ Sharad Agarwal ${ }^{4}$}

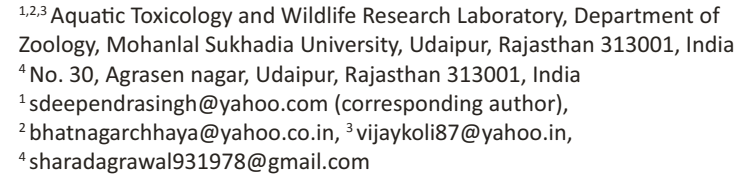

Cinereous Vulture Aegypius monachus is a member of the family Accipitridae and order Falconiformes. According to IUCN it has been categorized as "Near Threatened" (Birdlife International 2013). This species is resident in the high mountains of Pakistan (Baluchisthan) and in India it is distributed in Jammu and Kashmir (Gilgit), Punjab (Lahul), Assam and along the stretch of the Himalayan dry temperate zone (Ali \& Ripley 2001). It is also a rare winter visitor to Sindh and northern India, Kutch, northern Gujarat and the central part of the country, and Nepal (Grimmett et al. 1999; Ali \& Ripley 2001).

Ubeshwer $\left(24^{0} 37^{\prime} 08.04^{\prime \prime} \mathrm{N} \&\right.$ \& $73^{\circ} 33^{\prime} 45.41^{\prime \prime} \mathrm{E}$, elevation $872 \mathrm{~m}$ ) is a famous pilgrimage site located about $15 \mathrm{~km}$ north-west of Udaipur City and has lush green vegetation with scanty human presence. On 09 December 2011, we were birding in the hills of Ubeshwer and we saw two large dark black vultures at a distance at about $08.08 \mathrm{hr}$. They were sitting on a large rock (Image 1). Without disturbing them we approached the birds carefully. At about $60 \mathrm{~m}$, we stopped and observed the birds for about 25 minutes using binoculars (10x50 DPS). We also took photographs with the help of a Canon SX40 camera for further identification. After 25 minutes of our observation the birds flew away. The species was identified as the mature male Cinereous Vulture

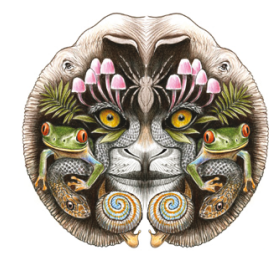

ISSN

Online 0974-7907 Print 0974-7893

\section{OPEN ACCESS} Aegypius monachus with the help of Grimmett et al. (1999) and Ali \& Ripley (2007). During the observation it was noted that the bird had uniformly black or blackish-brown body, except for pale areas on the head and bill (Image 1). The female of the same species was observed on the same site twice on 03 January 2012 and 05 February 2012, respectively.

The Cinereous Vulture is a winter visitor to the northern and central part of India but in the peninsular region it is identified as a vagrant (Rao 2006) and its presence has been identified from Andhra Pradesh (Choudhury 1990), Kerala (Kumar 1991) and Karnataka (Subramanya 2001). In Rajasthan State, it is documented from Jodhpur, Bikaner, Bharatpur and Jaisalmer districts during winter (Chhangani 2009; Kushwaha \& Kanaujia 2011; http://www.kolkatabirds.com/bharatpurlist. html). Many scientists have worked on the avian fauna (Sharma \& Tehsin 1994; Sharma 1998; Chhangani 2002; Saxena 2003; Sangha \& Devarshi 2006; Koli et al. 2011; Bhatnagar et al. 2007, 2011, 2013) of the southern part of the state and identified four species, namely, the Long-billed Vulture, the White-rumped Vulture, the Redheaded Vulture and the Egyptian Vulture. Therefore, the presence of this species in Udaipur District is a new addition to the bird list of the area.

DOI: http://dx.doi.org/10.11609/JoTT.o3432.5675-6 | ZooBank: urn:Isid:zoobank.org:pub:57A24416-D373-4FE3-A38E-392472550B67

Editor: Rajiv Kalsi, M.L.N. College, Haryana, India.

Date of publication: 26 April 2014 (online \& print)

Manuscript details: Ms \# 03432 | Received 12 December 2012 | Final received 04 April 2014 | Finally accepted 06 April 2014

Citation: Shekhawat, D.S., C. Bhatnagar, V.K. Koli \& S. Agarwal (2014). First record of Cinereous Vulture Aegypius monachus (Falconiformes: Accipitridae) from southern Rajasthan, India. Journal of Threatened Taxa 6(4): 5675-5676; http://dx.doi.org/10.11609/JoTT.03432.5675-6

Copyright: (c) Shekhawat et al. 2014. Creative Commons Attribution 3.0 Unported License. JoTT allows unrestricted use of this article in any medium, reproduction and distribution by providing adequate credit to the authors and the source of publication.

Funding: None.

Competing Interest: The authors declare no competing interests.
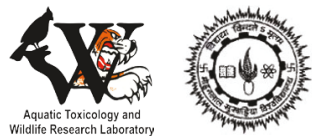

Acknowledgements: We thank Dr. Satish Kumar Sharma, Assistant Conservator of Forest, Udaipur, for his valuable comments on the manuscript. 


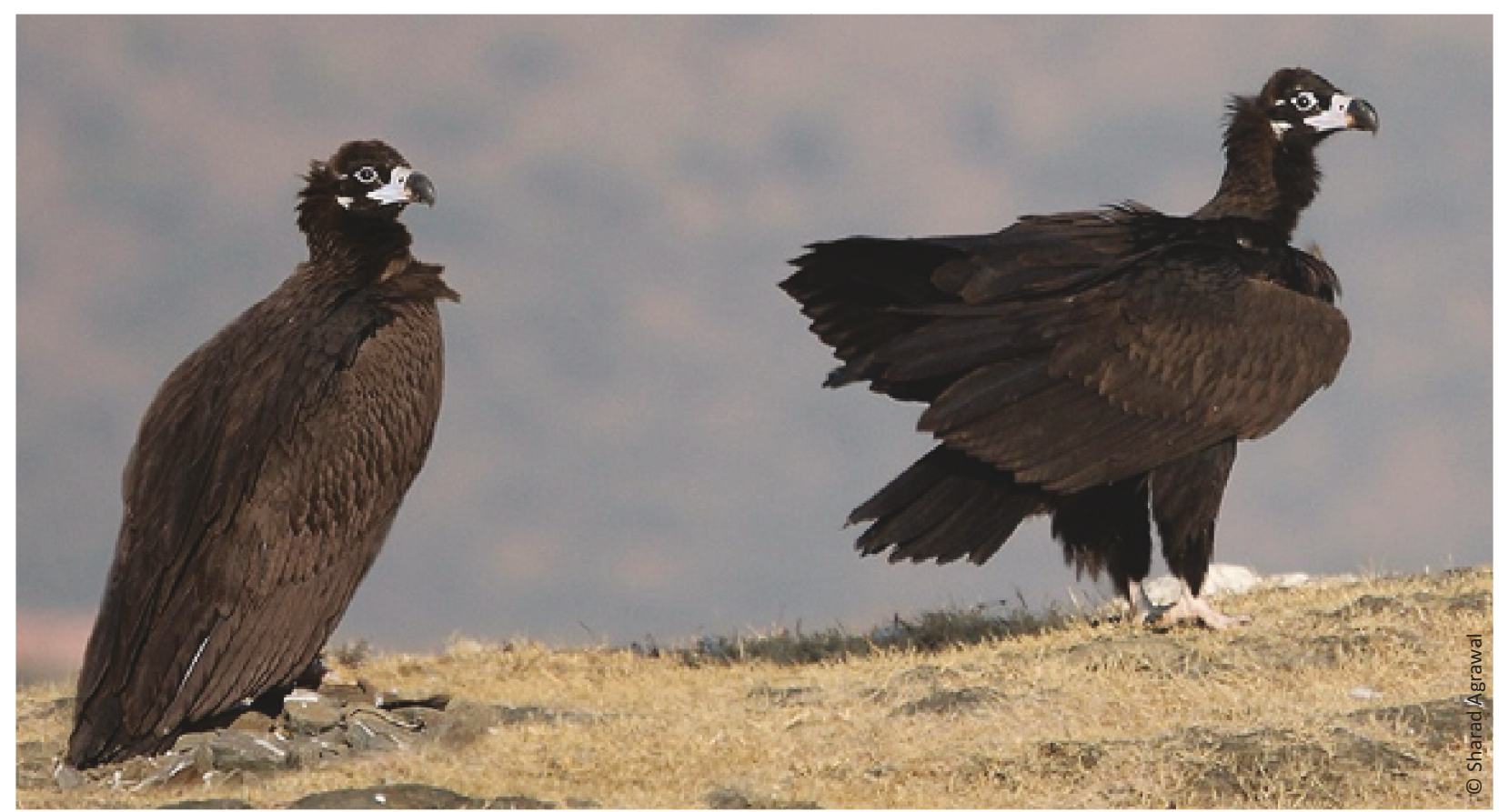

Image 1. Two Cinereous Vultures Aegypius monachus basking in Ubeshwer area, Udaipur

\section{References}

Ali, S. \& S. D. Ripley (2007). Handbook of the Birds of India and Pakistan. Bombay Natural History Society and Oxford University Press, 298-301.

Bhatnagar, C., V.K. Koli \& K. Jani (2011). Study on the distribution and occurrence of some threatened avifauna of Sajjangarh Wildlife Sanctuary, Udaipur, Rajasthan. Zoo's Print XXVI(6): 25-28.

Bhatnagar, C., D.S. Shekhawat \& V.K. Koli (2013). Second record of the Tricolored Munia Lonchura malacca from southern Rajasthan, India. Journal of the Bombay Natural History Society 110(1): 77-78.

Bhatnagar,C., K. Jani \& V. Sharma (2007). Vanishing habitat of aquatic birds in the city of lakes, Udaipur: a case study. The Indian Forester 133(10): 1395-1402.

Chhangani, A.K. (2002). Avifauna of Kumbhalgarh Wildlife Sanctuary in the Aravalli Hills of Rajasthan. Zoos' Print Journal 17(4): 764-768.

Chhangani, A.K. (2009). Status of vulture population in Rajasthan, India. Indian Forester 135(2): 239-251.

Choudhury, B.C. (1990). Capture of Cinereous Vulture Aegypius monachus in Karimnagar District, Andhra Pradesh. Mayura 7\&8: 49-50.

Grimmett, R., C. Inskipp \& T. Inskipp (1999). Birds of the Indian Subcontinent. Oxford University Press, New Delhi, 142pp.
Koli, V.K., C. Bhatnagar \& M. Yaseen (2011). Urban birds of Udaipur City (Rajasthan) and their conservation problems. Cheetal 49(2): 33-38.

Kumar, R.S.S. (1991). Cinereous Vulture Aegypius monachus (Linn.) in Pathanamthitta, Kerala. Journal of the Bombay Natural History Society 88(1): 111.

Kushwaha, S. \& A. Kanaujia (2011). Observations on Migratory and Residential vultures in Jorbeer, Rajasthan, India. Asian Journal of Experimenta Biological Sciences 2(3): 404-411.

Rao, J.P. (2006). Sighting of a Cinereous Vulture Aegypius monachus in Rangareddi District, Andhra Pradesh, India. Indian Birds 2(1):8-9.

Sangha, H.S. \& D. Devarshi (2006). Birds of Mount Abu Wildlife Sanctuary, Rajasthan, India. Indian Birds 2(2): 26-32.

Saxena, M.M. (2003). Birds of tribal and hilly district of Dungarpur. Newsletter for Birdwatchers 43(4): 54-55.

Sharma, S.K. (1998). Avian fauna of Sajjangarh Wildlife Sanctuary. Newsletter for Birdwatcher 38(2): 25-27.

Sharma, S.K. \& R. Tehsin (1994). Birds of southern Rajasthan. Newsletter for Birdwatcher 34(5): 109-113.

Subramanya, S. (2001). Cinereous Vulture Aegypius monachus (Linn.), Family Accipitridae, in Karnataka. Journal of the Bombay Natural History Society 98(2): 278.

http://www.kolkatabirds.com/bharatpurlist.html (accessed on 29 November 2012) 